\title{
Low-carbon governance, fiscal decentralization and sulfur dioxide emissions: Evidence from a quasi- experiment with Chinese heavy pollution enterprises
}

\section{Ping Guo}

Hunan University

Jin Li ( $\square$ ljin0502@hnu.edu.cn )

Hunan University https://orcid.org/0000-0003-4526-9786

Jinsong Kuang

Hunan University of Technology and Business

\section{Yifei Zhu}

Hunan University of Technology and Business

\section{Renrui Xiao}

Hunan University

Donghao Duan

Hunan University

\section{Baocong Huang}

Hunan University

\section{Research Article}

Keywords: Low-carbon pilot city, Fiscal decentralization, SO_2, DID, Sulfur dioxide treatment input, Heavy pollution enterprises

Posted Date: January 13th, 2022

DOI: https://doi.org/10.21203/rs.3.rs-1255683/v1

License: (c) (i) This work is licensed under a Creative Commons Attribution 4.0 International License. Read Full License

Version of Record: A version of this preprint was published at Sustainability on March 9th, 2022. See the published version at https://doi.org/10.3390/su14063220. 
experiment with Chinese heavy pollution enterprises

Author names

Ping Guo,Jin Li, Jinsong Kuang,Renrui Xiao,Baocong Huang,Donghao Duan, Yifei Zhu

Affiliations

School of Economics and Trade, Hunan University, Changsha 410205, Hunan, China

Ping Guo, Jin Li, Renrui Xiao \& Donghao Duan

School of Economics and Trade, Hunan University of Technology and Business, Changsha $\quad 410205$,Hunan,China

Baocong Huang

\section{Corresponding author}

Jin Li telephone:15898529150; email address: 1jin0502@hnu.edu.cn

\section{Acknowledgments}

This paper was supported by the National Natural Science Foundation of China (grant number: 42071161), the 
Provincial Education Department for Scientific Research (grant number: 19C1032).

23

24 
Abstract

This paper investigates the effects of enterprise environmental governance under low-carbon pilot policies in China with a difference in differences (DID) design. In examining the development of these policies, we focus on exploring their effects on sulfur dioxide emissions of heavily polluting enterprises based on prefectural city- and firm-level data from 2003-2014. Overall, the policies significantly increased enterprise $\mathrm{SO}_{2}$ emissions, and the underlying reason being that investments in $\mathrm{CO}_{2}$ control crowded out investment in $\mathrm{SO}_{2}$ control in enterprises in low-carbon pilot regions. We also find that the implementation of low-carbon pilot policies resulted in greater $\mathrm{SO}_{2}$ emissions from state-owned enterprises and enterprises in western regions than from non-state-owned enterprises and those in eastern regions. It is further found that fiscal decentralization and the associated mediating effect of market segmentation promote enterprises' $\mathrm{CO}_{2}$ control and inhibit their $\mathrm{SO}_{2}$ control. This study helps us reexamine the overall environmental effects of low-carbon policies and has implications for the revision and improvement of environmental governance policies in developing countries.

Keywords: Low-carbon pilot city;Fiscal decentralization; $\mathrm{SO}_{2}$; DID; Sulfur dioxide treatment input; Heavy pollution enterprises 


\section{Introduction}

With rapid economic development, air pollution caused by industrial production in China has become increasingly serious (Hao et al. 2018; Mujtaba and Shahzad 2021), with air pollution problems caused by emissions of carbon dioxide $\left(\mathrm{CO}_{2}\right)$ and sulfur dioxide $\left(\mathrm{SO}_{2}\right)$ becoming a particular focus of attention (Zhang et al. 2020). Poor air quality can lead to major public health and welfare problems (WHO 2016). Many cities around the world have constructed low-emission zones as an important measure to enhance urban competitiveness, reduce greenhouse emissions, decrease air pollution, and improve the resident well-being. In terms of academic research, scholars outside China have extensively investigated the role of low-emission zones in pollution governance (Ellison et al. 2013; Wolff 2014; Gehrsitz 2017). Ellison et al. (2013) explored the relationship between air quality in low-emission zones and that of surrounding regions before and after policy implementation and assessed the impact of low-emission policies implemented in London on regional air quality. Wolff (2014) assessed the impact of low-emission area policies implemented in Europe on regional air quality by using a difference-in-differences (DID) design to determine the treatment effects across regions and over time. Gehrsitz (2017) also used DID to investigate the effect of lowemission zone policies implemented in Germany on air quality and infant mortality. All of the above studies found that low-emission policies significantly improved air quality in the regions where the policies were implemented. To improve air quality and control environmental pollution, the Chinese government has also developed and implemented a series of environmental governance measures, with the Low-Carbon Pilot Policy (LCPC) being one of the most important institutional arrangements. In July 2010, the Chinese government issued a notice on the first round of low-carbon provincial and municipal pilot programs and areas, including Guangdong, Guiyang and 13 other provinces and cities. In November 2012, the "Notice on the Second Batch of Low-Carbon Provincial and Municipal Pilots" was issued, covering 29 provinces and cities such as Hainan and Zhenjiang. Numerous studies 
have shown that the LCPC has significantly reduced $\mathrm{CO}_{2}$ emissions (Lin et al. 2014; Dai and Cao 2015; Feng et al.

2021; Hong et al. 2021). However, whether this policy can reduce emissions of $\mathrm{SO}_{2}$ and gases other than $\mathrm{CO}_{2}$ and

64

65

66

67

68

69

70

71

72

73

74

75

76

77

78

79

80

improve overall environmental management is still an important issue of study that has not yet attracted active attention in academia.

Research literature focusing on the impact of the $\mathrm{LCPC}$ on $\mathrm{SO}_{2}$ emissions is still scant. As a

comprehensive environmental regulatory tool, the LCPC differs from traditional single environmental regulations in that its goal is to achieve emission reductions of $\mathrm{CO}_{2}, \mathrm{SO}_{2}$ and other pollutant gases (Tan et al. 2017; Chen et al. 2021) but it requires greater reductions of $\mathrm{CO}_{2}$ than of $\mathrm{SO}_{2}$. Song et al. (2019) used single-period DID to analyze the relationship between the LCPC and urban air pollution in China and found that the LCPC reduced the air pollution index (API) ${ }^{1}$ of pilot cities by fostering upgrades and innovation in the industrial structure. However, Peng et al. (2020) found that the LCPC has no significant effect on $\mathrm{SO}_{2}$ emissions in small and medium-sized cities and megacities based on a single-period DID.

It can be seen that the depth and breadth of the existing literature is far from adequate in terms of the mechanisms whereby the LCPC impacts $\mathrm{SO}_{2}$ emissions. The LCPC places environmental regulatory pressure on enterprises in pilot regions and increases their actual pollution emission costs (Chen et al. 2021). Regional governments attach much more importance to $\mathrm{CO}_{2}$ than $\mathrm{SO}_{2}$ emission reductions (Feng et al. 2021). On the one hand, enterprises may invest in technology and equipment to reduce $\mathrm{CO}_{2}$ and $\mathrm{SO}_{2}$ emissions. On the other hand, to maximize profit and meet the higher $\mathrm{CO}_{2}$ reduction targets, enterprises may increase their capital investment in $\mathrm{CO}_{2}$ governance, which may crowd out funds for governance of other polluting gases such as $\mathrm{SO}_{2}$ and result in an

\footnotetext{
${ }^{1}$ The urban API includes a combined assessment of $\mathrm{PM}_{10}, \mathrm{SO}_{2}, \mathrm{NO}_{2}$, etc.
} 
increase in enterprise emissions of these pollutants.

In addition, most of the existing literature evaluates the effects of the LCPC by using single-period DID designs, which may suffer from endogeneity problems. Specifically, the LCPC has been implemented in rounds, and samples covering different periods have different characteristics, such as differences in economic development levels. These variables may affect $\mathrm{SO}_{2}$ emissions, and their omission could bias the estimation results obtained. Therefore, to examine the development of the LCPC, this paper uses data on prefecture-level cities and enterprises in China from 2003 to 2014 and applies a multiperiod DID to investigate the relationship between the LCPC and $\mathrm{SO}_{2}$ emissions. It attempts to explore the following core issues: Does the LCPC curb $\mathrm{SO}_{2}{ }^{2}$ emissions from heavily polluting enterprises? What are the mechanisms whereby $\mathrm{SO}_{2}$ emissions from heavy polluters are affected? Answering the above questions will help clarify the relationship between low-carbon policies and pollution emissions and help us re-examine the overall environmental governance effects of the LCPC. The potential contributions of this paper relate mainly to the following three aspects. First, in terms of the research perspective, this paper focuses on assessing the impact of the $\mathrm{LCPC}$ on $\mathrm{SO}_{2}$ emissions from heavy polluters, complementing previous studies on China that have focused on the role of the LCPC in reducing $\mathrm{CO}_{2}$ emissions. Previous studies have found that the LCPC can effectively reduce $\mathrm{CO}_{2}$ emissions (Song et al. 2018), but the impact on $\mathrm{SO}_{2}$ emissions remains to be verified. Moreover, this paper enriches and complements the research on the impact of the LCPC on cleaner production in heavily polluting enterprises. In particular, most of the literature on the impact of low-carbon policies on regional air quality has focused on

2 It would be preferable to examine the impacts on more than one pollutant. However, for industrial pollution, the central government of China previously focused on only $\mathrm{SO}_{2}$ among air pollutants and chemical oxygen demand (COD) for water pollution. 
developed countries, and few studies have focused on China, the largest developing country. Therefore, this quasinatural experimental study of the LCPC based on a sample of Chinese firms is innovative, providing new empirical evidence for developing countries and complementing existing studies.

Second, from a data and methodological perspective, one of the challenges commonly faced in existing literature evaluating environmental policy effects is endogeneity problems. Due to the late start of environmental policies in China and data limitations, there is less literature examining the effects of environmental remediation that effectively addresses these endogeneity problems. Thus, this paper uses a multiperiod DID approach based on firmlevel pollution data for the period 2003-2014 and takes the LCPC as a quasinatural experiment to better alleviate endogeneity problems and data limitations, providing new empirical and methodological ideas for related studies. Third, the mechanism by which the LCPC affects the $\mathrm{SO}_{2}$ emissions of heavy polluters is explored. The mechanism analysis finds that the LCPC has a crowding-out effect on financial investment for the treatment of $\mathrm{SO}_{2}$. This decrease in investment in $\mathrm{SO}_{2}$ control causes an increase in $\mathrm{SO}_{2}$ emissions. Moreover, existing studies suggest that the LCPC can influence the environmental investment decisions of enterprises (Guo et al. $2020 \mathrm{Xu}$ and Cui 2020; Ji et al. 2021); however, whether the LCPC influences the $\mathrm{SO}_{2}$ emissions of heavy polluters has not been demonstrated. Therefore, we test the mechanism with a moderating effect model. Our findings suggest that the LCPC increases financial investment in the treatment of $\mathrm{CO}_{2}$ and crowds out investment in the treatment of $\mathrm{SO}_{2}$, which in turn increases $\mathrm{SO}_{2}$ emissions among heavily polluting enterprises.

The remainder of this paper is structured as follows: The second part introduces the LCPC with respect to its formulation, implementation background and potential effect mechanism. The third part presents the data used in the empirical study and sets up an econometric regression model to implement the identification strategy. The fourth part reports the analysis of the empirical results and conducts robustness and mechanism tests. The fifth part offers a 
heterogeneity analysis. The sixth part presents further discussion from the perspective of fiscal decentralization, and

121 the seventh part offers the conclusion and policy implications.

\section{Policy background and research hypotheses}

\subsection{China's low-carbon pilot policy (LCPC)}

The economic development of China's prefecture-level cities has been accompanied by a yearly increase in greenhouse gas and pollution emissions. In this context, to control emissions of greenhouse and polluting gases, China has successively introduced a series of energy conservation and emission reduction policies. In 2010, the National Development and Reform Commission issued the "Notice on the Piloting of Low-Carbon Provinces and scientific and technological innovation, upgrade growth patterns, and develop green industries (Liu and Qin 2016).

The first round of pilots was implemented from 2010, with 13 provinces and cities selected, including Guangdong, pilots in 2017.

\footnotetext{
${ }^{3}$ Beijing, Shanghai, Hainan, Shijiazhuang, Qinhuangdao, Jincheng, Hulunbeier, Jilin, Daxinganling, Suzhou, Huaian, Zhenjiang, Ningbo, Wenzhou, Chizhou, Nanping, Jingdezhen, Ganzhou, Qingdao, Jiyuan, Wuhan, Guangzhou, Guilin, Guangyuan, Zunyi, Kunming, Yan'an, Jinchang, and Urumuqi.
} 
are some institutional weaknesses, especially the lack of a clear definition of low-carbon pilot areas, an effective evaluation system and comprehensive development goals and the implementation of multiple parallel programs that confuse the process (Khanna et al. 2014). In turn, local governments lack awareness over the progress of the lowcarbon economic transition and clarity surrounding the concepts of energy conservation and a circular, low-carbon, sustainable economy. This irrational design and consequent implementation problems lead to distortions in resource

143 allocation and efficiency losses, which can easily lead to a green paradox (Sinn 2008). At the pilot region level, the LCPC imposes clear $\mathrm{CO}_{2}$ emission reduction requirements (Feng et al. 2021) but advocates only voluntary reductions in other emissions such as $\mathrm{SO}_{2}$ (Song et al. 2021). Although most pilot regions use a combination of three regulatory tools, namely, mandates, market tools and voluntary initiatives, to

147 pursue policies (Wang et al. 2015), the specific implementation process uses mainly mandates (Xu and Cui 2020): for example, shutdowns of enterprises violating $\mathrm{CO}_{2}$ emission standards, setting of mandatory $\mathrm{CO}_{2}$ emission intensity targets per unit of GDP, and delegation of $\mathrm{CO}_{2}$ emission control to lower levels of government and enterprises (Song et al. 2021). In addition, government officials in the pilot regions generally regard the central government's assessment targets for $\mathrm{CO}_{2}$ emission reduction as their top priority because compliance affects their personal careers. In addition, they pay no attention to emissions other than those targeted for assessment unless they become components of the higher-level assessment (Qi 2013; NDRC 2014). As a result, the intensity of $\mathrm{CO}_{2}$ emission control may be greater than that of $\mathrm{SO}_{2}$ emission control in low-carbon pilot regions in China. For enterprises, as rational economic agents, the optimal choice in complying with the LCPC is to increase their investment in $\mathrm{CO}_{2}$ treatment. This inevitably requires significant financial support, forcing enterprises to redirect their environmental funds to reducing $\mathrm{CO}_{2}$ emissions. However, many enterprises in heavily polluting industries have limited environmental protection expenditures because of financial and technological constraints 
159 (Liu et al. 2021, and enterprises may reconfigure these expenditures in the presence of regulation. This may make it

160 difficult to increase capital investment in the treatment of $\mathrm{SO}_{2}$ in line with increases in enterprise production. Thus,

161 the implementation of the LCPC and increase in investment in $\mathrm{CO}_{2}$ control is likely to be accompanied by a

162 crowding-out effect on investment in $\mathrm{SO}_{2}$ control, with $\mathrm{SO}_{2}$ emissions among heavy polluters in pilot areas

163 correspondingly increasing.

164

165

\subsection{Research hypotheses}

166

Drawing on the framework of Berman and Bui (2001) and Liu et al. (2021), we construct a production function that

167 includes "quasi-fixed" input factors, calculate firms' pollution emissions, and then introduce environmental regulations into the pollutant function. In particular, according to Brown and Christensen (1980), "quasi-fixed" input factors can be determined by exogenous constraints. As the main tool for the LCPC, the command-and-control policy requires firms to meet emission standards by a deadline, and firms must invest more in $\mathrm{CO}_{2}$ emission control in the short term or have their operations suspended or even shut down. Therefore, we consider the pollutant treatment inputs for LCPC compliance to be "quasi-fixed" input elements. quantity $k$ is the sum of the "quasi-fixed" input $\mathrm{z}\left(\mathrm{z}=z_{c}+z_{S}\right)$ and the fixed input $u$. The production function has the following form:

177 where $q$ is the output, 1 is the labor input, and $z_{c}, z_{s}$ are the $\mathrm{CO}_{2}$ treatment input the $\mathrm{SO}_{2}$ treatment input of the

178 LCPC, which we consider "quasi-fixed" input factors. We use a linear equation to approximate: 
$181 E=v^{*} q$

mechanisms:

$190 \quad \frac{d E}{d R}=v \alpha \frac{d u}{d R}+v \beta \frac{d l}{d R}+v \tau \frac{d z_{c}}{d R}+v \tau \frac{d z_{s}}{d R}$ reduction technology and emission reduction equipment, which are not affected by the environmental regulation in the short run. Therefore, the first and second terms in equation (6) are dropped, leaving the third and fourth terms. These terms reflect the impact of the $\mathrm{LCPC}$ on the "quasi-fixed" $\mathrm{CO}_{2}$ and $\mathrm{SO}_{2}$ treatment inputs, respectively. $\left(z_{s}\right.$, i.e., $\mathrm{SO}_{2}$ governance input) by crowding out "quasi-fixed" $\mathrm{CO}_{2}$ treatment inputs. 
In addition, it has been shown (Copeland and Taylor 2013) that $d E / d z>0$, so that we can derive $\frac{d E_{C}}{d R}>0$

201 and $\frac{d E_{S}}{d R}<0$. It is clear that the LCPC has a crowding-out effect on the "quasi-fixed" $\mathrm{SO}_{2}$ control inputs. If the

202 "quasi-fixed" $\mathrm{SO}_{2}$ control input is reduced, $\mathrm{SO}_{2}$ emissions increase. Based on this, this paper proposes the

203 following.

for $\mathrm{CO}_{2}$ governance. The low-carbon planning programs of the pilot regions have proposed various low-carbon

financial policies to reduce $\mathrm{CO}_{2}$ emissions, including special funds for low-carbon development; industry subsidies,

preferential loans with reduced interest rates, and specific loan funding arrangements for $\mathrm{CO}_{2}$ reduction; and low-

carbon tax exemptions. These financial policies can increase investment in low-carbon projects and direct more

capital to low-carbon industries and production processes by allocating capital among different types of industries,

(Wang et al. 2019). This low-carbon finance policy focuses on management of $\mathrm{CO}_{2}$ emissions and requires 
treatment inputs and inhibit $\mathrm{SO}_{2}$ treatment inputs through a crowding-out effect on $\mathrm{SO}_{2}$ reduction inputs.

\section{Data and empirical strategy}

\subsection{Data sources}

To comprehensively examine the impact of the LCPC on the $\mathrm{SO}_{2}$ emissions of heavily polluting enterprises and its influence mechanism, this paper integrates multiple sets of statistical data and finally integrates them to construct a comprehensive database including Chinese industrial enterprise data, enterprise pollution data, and municipal-level statistics. The details are as follows.

First, we use data on Chinese industrial enterprises. The data come from the National Bureau of Statistics, covering all industrial enterprises above a certain size. This database contains basic information such as the enterprise name, legal person code, enterprise address and many financial indicators such as total assets and sales.

This database, which offers the advantages of a large sample size and rich information, has been widely used in recent studies. Referring to Brandt et al. $(2012,2017)$ and others, the following processing was performed on the database of industrial enterprises before matching: (1) enterprises with duplicate legal person codes were eliminated; (2) enterprises whose data do not comply with general accounting standards (e.g., had current assets exceeding total assets, net fixed assets greater than total assets, or a missing number of employees) were eliminated; (3) enterprises with missing key indicators were eliminated; (4) the 4-digit industry codes from 1998-2014 were standardized according to the industry cross-reference table published by the National Bureau of Statistics; (5) a cross-year panel was constructed through the method of sequential matching; and (6) enterprises with a large number of missing data were removed. 
243 (CESD) offers the most detailed environmental statistics available in China, covering the whole country, and is

244 considered to be the most comprehensive and reliable environmental microeconomic database in the country (Zhang

245 et al. 2018). The Ministry of Environmental Protection (MEP) has established an environmental information system

246 covering all major emission sources. However, the CESD has long been confidential and was only recently made

247 available to researchers (Chen et al. 2018a). Each company self-reports data on a seasonal basis, which is then

248 compiled by the MEP. Local environmental protection agencies (EPAs) confirm the data quality through

249 unannounced inspections and other monitoring activities. The local EPA then generates a final report that is sent to

250 the provincial EPA. After review and approval, the certification information is sent to the MEP. National and

251 provincial environmental authorities often review local EPAs' statistical work via a variety of methods, including

252 random spot checks. If problems are found, on-site inspections are conducted when necessary. Higher-level

253 governments also directly conduct flight inspections, cross-checks, and on-site verifications of enterprise pollution

254 emissions. The CESD is the most comprehensive environmental set of microdata in China, covering approximately

$25585 \%$ of annual emissions of major pollutants (e.g., $\mathrm{SO}_{2}$ and $\mathrm{COD}$ ). The CESD contains basic enterprise information

256 (e.g., enterprise name, legal person code (Chen et al. 2018b), district code and industry code), pollution emissions,

257 environmental equipment (e.g., number of exhaust gas treatment facilities and wastewater treatment facilities), and

258 other environmental information of the enterprise (e.g., pollutant removal, treatment capacity, and operating costs of

259 abatement facilities). For our empirical analysis, we use CESD information on $\mathrm{SO}_{2}$ emissions, number of $\mathrm{SO}_{2}$

260 exhaust treatment facilities (Cole and Elliott 2007), statistical year, ownership type, area code, and industry code. 
2014, the sample period for this study ends in 2014, and the first- and second-round pilot municipalities are selected as the treatment group. We exclude the third round of pilot cities from our study analysis because they are still in the initial stage of the policy implementation and have limited data available. At the enterprise level, data on $\mathrm{SO}_{2}$ emissions, nitrogen oxide emissions, the number of $\mathrm{CO}_{2}$ and other waste gas treatment facilities, and the number of $\mathrm{SO}_{2}$ waste gas treatment facilities of heavily polluting enterprises were obtained from the CESD, and other data were obtained from the China Industrial Enterprises Database. At the city level, city data were obtained from the China City Statistical Yearbook for previous years. This paper matches the CESD, China industrial enterprise database and prefecture-level city data based on the legal person code, enterprise name and enterprise location. In this paper, only heavily polluting enterprises are retained in the industry screening. To mitigate the influence of outliers on our results, we winsorize all continuous variables at the 1st and 99th percentiles.

\subsection{Model specification}

The question explored in this paper is the effect of the $\mathrm{LCPC}$ on $\mathrm{SO}_{2}$ emissions from heavy polluters. To address the endogeneity problems commonly faced in the literature, this paper constructs a multiperiod double-difference model using the LCPC as a quasinatural experiment, divides the study population into a treatment group (areas where the policy has been implemented) and a control group (areas where the policy has not been implemented), and removes the time trend. The net effect of the policy implementation is identified by differentiating the time trend before and after policy implementation and the difference between the treatment and control groups to isolate the policy effect from the influence of time-varying and unobservable factors. This method has been widely used in existing policy studies (Song et al. 2019). In this paper, the provinces and cities included in the scope of the first two rounds of low- 
carbon pilot projects are used as the treatment group, and the remaining provinces and cities are used as the control group to quantitatively assess the effect of $\mathrm{LCPC}$ implementation on $\mathrm{SO}_{2}$ emissions from heavily polluting enterprises. The specific model settings are as follows:

post $_{i t}$ is used to distinguish the years before and after the low-carbon pilot, where post $_{i t}=0$ means the year

before the pilot and post $_{i t}=1$ the year after the pilot; treat $_{i t}=1$ indicates areas where the policy has been

implemented and treat $_{i t}=0$ areas where the policy has not implemented; and $D I D_{i t}$ is the interaction term between

treat $_{i t}$ and post $t_{i t}$, which takes the values 0 or 1 . If firm $i$ belongs to the low-carbon pilot region in year $t, D I D_{i t}$ is geographical control variables; $\mu_{i}$ represents enterprise fixed effects, $\mu_{t}$ year fixed effects, and $\varepsilon_{i t}$ the random error term. In the model, $\ln \left(\mathrm{SO}_{2}\right)_{i t}$ represents the logarithm of $\mathrm{SO}_{2}$ emissions from enterprise $i$ in year $t$.

\subsection{Variable selection}

\subsubsection{Dependent variable}

$\mathrm{SO}_{2}$ emissions ( $\operatorname{lnSO} \mathrm{O}_{2}$ ). Drawing on Liu et al. (2021), we use enterprise $\mathrm{SO}_{2}$ emissions for this indicator. $\mathrm{SO}_{2}$ most 
LCPC treatment $(D I D)$. The key independent variable is the dummy variable $D I D$, obtained based on the list of lowcarbon cities in the "Notice on Conducting the Pilot Program of Low-Carbon Provinces and Cities" and the time of program establishment.

\subsubsection{Control variables}

312 Control variables $(\mathrm{Z})$. Considering that other factors at the enterprise and municipal levels may have potential effects

313 on the $\mathrm{SO}_{2}$ emissions of heavy polluters, we select a series of enterprise economic characteristics and municipal-

314 level influencing factors as control variables in this paper. (i) Enterprise size (lnsize). It has been shown in the

315 literature that larger enterprises make more stable governance investments to meet environmental protection

316 standards for the sustainability of their development ( $\mathrm{Li}$ and $\mathrm{Zheng} 2016$; Bu et al. 2020). In this paper, the

317 logarithm of total firm capital at the end of the year is used to measure the firm size. (ii) Firm age (age). The age of a

318 firm usually represents its maturity, and studies have shown that more mature firms tend to have stronger operational

319 capabilities (Huang et al. 2021). In this paper, the number of years that a firm has been in business since its inception

320 is used to measure firm age. (iii) Firm performance-related variables. Drawing on Cai et al. (2019), this paper

321 controls for both firm capital intensity (capital) and firm profit (profit) to account for the influence of factors such as

322 firm performance. Capital intensity is expressed as the ratio of the firm's fixed assets to total assets; corporate profit

323 is expressed as the logarithm of the firm's total profit. (iv) Relevant variables at the city level. To account for the

324 possible effects of regional openness, the economic development level and industrial structure changes at the city

325 level on the $\mathrm{SO}_{2}$ emissions of heavily polluting enterprises (Yu and Zhang 2017; Jin and Shen 2018), this paper 

our sample period.

Table 1. Descriptive statistics

\begin{tabular}{|c|c|c|c|c|c|}
\hline & (1) & (2) & (3) & (4) & $(5)$ \\
\hline VARIABLES & $\mathrm{N}$ & mean & sd & $\min$ & $\max$ \\
\hline \multicolumn{6}{|c|}{ Panel A: Descriptive statistics of full sample } \\
\hline age & 535,515 & 11.58 & 9.455 & 2 & 39 \\
\hline capital & 535,140 & 0.339 & 0.234 & 0 & 0.784 \\
\hline profit & 388,003 & 8.174 & 2.046 & 4.369 & 11.72 \\
\hline lnsize & 535,140 & 11.10 & 1.517 & 8.654 & 14.09 \\
\hline lncityfdi & 527,549 & 0.192 & 0.173 & 0.0111 & 0.580 \\
\hline lnpgdp & 534,762 & 10.36 & 0.698 & 9.046 & 11.49 \\
\hline lndustry & 535,095 & 3.943 & 0.147 & 3.630 & 4.170 \\
\hline $\ln \mathrm{SO}_{2}$ & 390,788 & 7.217 & 3.837 & 0.177 & 12.72 \\
\hline \multicolumn{6}{|c|}{ Panel B: Descriptive statistics of treatment group } \\
\hline age & 264,298 & 12.12 & 9.514 & 2 & 39 \\
\hline capital & 264,021 & 0.334 & 0.232 & 0 & 0.784 \\
\hline profit & 188,909 & 8.235 & 2.071 & 4.369 & 11.72 \\
\hline lnsize & 264,021 & 11.21 & 1.520 & 8.654 & 14.09 \\
\hline Incityfdi & 262,098 & 0.254 & 0.191 & 0.0111 & 0.580 \\
\hline lnpgdp & 263,950 & 10.52 & 0.704 & 9.046 & 11.49 \\
\hline lndustry & 263,856 & 3.934 & 0.146 & 3.630 & 4.170 \\
\hline $\ln \mathrm{SO}_{2}$ & 185,984 & 7.134 & 3.847 & 0.177 & 12.72 \\
\hline
\end{tabular}

Panel C: Descriptive statistics of control group 


\begin{tabular}{cccccc} 
age & 271,217 & 11.05 & 9.366 & 2 & 39 \\
capital & 271,119 & 0.345 & 0.235 & 0 & 0.784 \\
profit & 199,094 & 8.116 & 2.021 & 4.369 & 11.72 \\
lnsize & 271,119 & 10.99 & 1.506 & 8.654 & 14.09 \\
lncityfdi & 265,451 & 0.131 & 0.125 & 0.0111 & 0.545 \\
lnpgdp & 270,812 & 10.20 & 0.654 & 9.046 & 11.49 \\
lndustry & 271,239 & 3.951 & 0.147 & 3.630 & 4.170 \\
$\ln \mathrm{S}_{2}$ & 204,804 & 7.293 & 3.827 & 0.177 & 12.72 \\
\hline
\end{tabular}

Note: Continuous variables are winsorized at $1 \%$ and $99 \%$.

\section{Results}

\subsection{Main results}

341 The results of the baseline regression of the effect of the $\mathrm{LCPC}$ on $\mathrm{SO}_{2}$ emissions are shown in Table 2. $\operatorname{lnSO} \mathrm{O}_{2}$ is

342 the explanatory variable. Column (1) shows that the coefficient of the core explanatory variable is 0.08 and significant at the $1 \%$ confidence level after we add only the core explanatory variable $D I D$ and the two-way year and region fixed effects, indicating that the low-carbon pilot reform increases the $\mathrm{SO}_{2}$ emissions of heavily polluting enterprises in the jurisdiction by $8 \%$. The coefficient of the core explanatory variable is 0.138 and significant at the column (2), indicating that the low-carbon pilot reform increases the $\mathrm{SO}_{2}$ emissions of heavily polluting firms in the jurisdiction by $13.8 \%$ after the firm-level variables are controlled for. Column (3) further controls for three 
353 indicates that the LCPC is significantly and positively related to the $\mathrm{SO}_{2}$ emissions of heavily polluting enterprises,

354 indicating that hypothesis 1 is valid.

355 Table 2. Baseline results

\begin{tabular}{lccc}
\hline & $(1)$ & $(2)$ & $(3)$ \\
\hline DID & $0.080^{* * * *}$ & $0.138^{* * *}$ & $0.143^{* * *}$ \\
scale_ass & $(0.010)$ & $(0.013)$ & $(0.013)$ \\
& & $0.105^{* * *}$ & $0.103^{* * *}$ \\
profit & & $(0.007)$ & $(0.007)$ \\
& & $0.015^{* * *}$ & $0.014^{* * *}$ \\
capital & & $(0.003)$ & $(0.003)$ \\
& & -0.001 & -0.001 \\
age & & $(0.019)$ & $(0.019)$ \\
& & 0.001 & 0.001 \\
lncityfdi & & $(0.001)$ & $(0.001)$ \\
& & & $0.447^{* * *}$ \\
lncityrjgdp & & & $(0.087)$ \\
& & & 0.032 \\
lncitycyjg & & & $(0.026)$ \\
& & & -0.022 \\
Constant & & & $(0.054)$ \\
Year FE & $10.050^{* * *}$ & $8.785^{* * *}$ & $8.533^{* * *}$ \\
Observations & $(0.009)$ & $(0.072)$ & $(0.266)$ \\
R squared & YES & YES & YES \\
\hline
\end{tabular}

356 Notes: This table reports regression coefficients and robust standard errors (clustered within cities and robust to

357 heteroskedasticity) in parentheses for the full sample regression results. Continuous variables are winsorized at $1 \%$

358 and 99\%. Firm-year fixed effects are included in the regression estimations. ***, **, and * represent significance

359 levels of 1,5 , and $10 \%$, respectively. These notes apply to all subsequent tables.

360

\subsection{Robustness checks}


364

An important assumption required for the policy assessment using the multiperiod double-difference method is that the time trends of the treatment and control groups would have been the same in the absence of the policy shock, and thus, a parallel trend test of this assumption is required. For this purpose, we set up the following econometric model:

$\ln \left(S O_{2}\right)_{i t}=\alpha+\beta_{2} D I D_{i t}^{-4}+\beta_{3} D I D_{i t}^{-3}+\cdots+\beta_{9} D I D_{i t}^{4}$

$+\gamma Z+\mu_{i}+\mu_{t}+\varepsilon_{i t}$

In the model, $D I D_{i t}^{ \pm j}$ is a series of dummy variables, $D I D_{i t}^{-j}$ takes the value of 1 when the treatment group is in year $j$ before the low-carbon pilot reform, and $D I D_{i t}^{+j}$ takes the value of 1 when it is in year $j$ after the low-carbon pilot reform; otherwise, $D I D_{i t}^{ \pm j}$ takes the value of 0 . We take the year before the low-carbon pilot reform as the reference category for the coefficient of $D I D_{i t}^{ \pm j}$ in the regression. This coefficient indicates whether there is a significant difference in the trend of $\mathrm{SO}_{2}$ emissions between the treatment and control groups of enterprises in year $j$ before and after the low-carbon pilot reform in comparison with this difference in the control group. To represent the estimation results visually, we present the trend of the coefficient of $D I D_{i t}^{ \pm j}$ in Fig. 1, with the horizontal axis indicating the years before and after the distance from the pilot and the vertical axis indicating the magnitude of the estimated value.

From Figure 1, it can be seen that the coefficients of $D I D$ are not significant when $j=-4,-3,-2$, and -1 , which means that there is no significant difference in the trend of $\mathrm{SO}_{2}$ emission changes of enterprises in the treatment and control groups before the low-carbon pilot reform, so the hypothesis of parallel trends cannot be rejected. In the time after the low-carbon pilot reform, the coefficient of $D I D_{i t}^{+j}$ on enterprise $\mathrm{SO}_{2}$ is significant at the $1 \%$ level from the year of reform, which means that the low-carbon pilot reform intensifies enterprise $\mathrm{SO}_{2}$ emissions basically 
without a time lag and the effect can last for quite a long period of time.

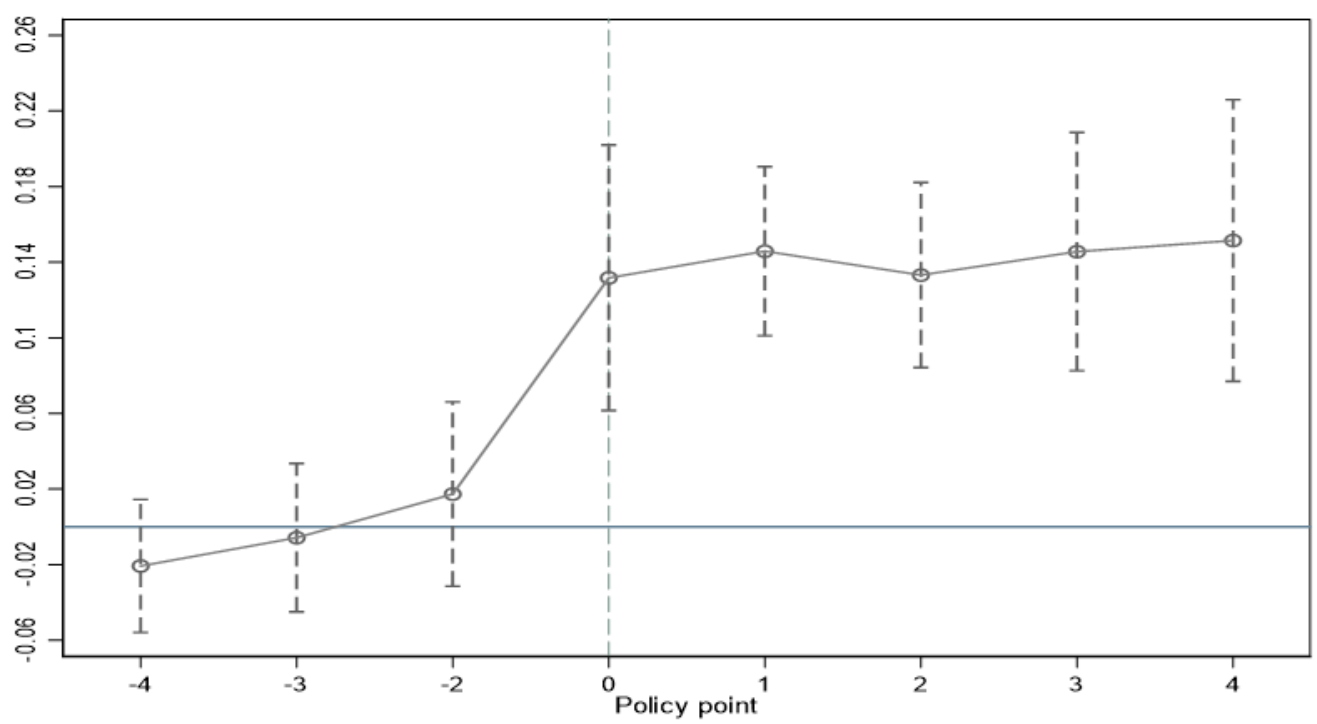

Fig. 1 Parallel trend test. Data source: Drawn by the author

\subsubsection{Alternative estimation method}

389 Considering that the sample used in this paper uses matched data at the firm and the prefectural city level, we adopt

a standard error clustering analysis to circumvent the heteroskedasticity problem. Specifically, the sample standard

errors are clustered at the prefectural city level, and the results show that the significance of the estimated

394 Table 3. Robustness tests

\begin{tabular}{c|c|c|c}
\hline & \multicolumn{2}{|c|}{ Inspection method } & \\
\hline \multirow{3}{*}{$(1)$} & Alternative estimation & $\begin{array}{c}\text { Adopting standard } \\
\text { error clustering } \\
\text { method }\end{array}$ & $\begin{array}{c}0.143^{* * *} \\
\text { analysis at the } \\
\text { prefecture level to } \\
\text { circumvent the }\end{array}$ \\
& & $(0.021)$ \\
\hline
\end{tabular}




\begin{tabular}{|c|c|c|c|}
\hline & & $\begin{array}{l}\text { heteroskedasticity } \\
\text { problem }\end{array}$ & \\
\hline (2) & $\begin{array}{l}\text { Controls for potential } \\
\text { omitted variables }\end{array}$ & $\begin{array}{l}\text { Adding firm- and } \\
\text { prefecture-level } \\
\text { control variables }\end{array}$ & $\begin{array}{c}0.132 * * * \\
(0.015)\end{array}$ \\
\hline \multirow{2}{*}{ (3) } & \multirow{2}{*}{$\begin{array}{c}\text { Impact of the } \mathrm{LCPC} \text { on } \\
\text { total } \mathrm{SO}_{2} \text { and } \mathrm{CO}_{2} \\
\text { emissions at the municipal } \\
\text { level }\end{array}$} & $\begin{array}{l}\text { Using the logarithm of } \\
\mathrm{CO}_{2} \text { emissions from } \\
\text { prefecture-level cities }\end{array}$ & $\begin{array}{c}-0.060 * * * \\
(0.001)\end{array}$ \\
\hline & & $\begin{array}{l}\text { Using the logarithm of } \\
\mathrm{SO}_{2} \text { emissions from } \\
\text { prefecture-level cities }\end{array}$ & $\begin{array}{c}0.028 * * * \\
(0.003)\end{array}$ \\
\hline (4) & $\begin{array}{c}\text { Alternative explanatory } \\
\text { variable }\end{array}$ & $\begin{array}{l}\text { Using the logarithm of } \\
\text { nitrogen oxide } \\
\text { emissions }\end{array}$ & $\begin{array}{c}0.239 * * * \\
(0.020)\end{array}$ \\
\hline
\end{tabular}

395

\subsubsection{Controls for potential omitted variables}

Although we have included firm and year fixed effects and controlled for key indicators at the prefecture level, there is still a possibility of omitted variable bias. Therefore, the firm-level variable corporate indebtedness (lndebts) is added to the basic measurement equation. Corporate indebtedness reflects the market's evaluation of a firm's creditworthiness (Meuleman and De Maeseneire 2012), and a moderately indebted operation allows firms to have more abundant funds for activities such as technical equipment improvement and process upgrades. This indicator is measured in this paper by the logarithm of the firm's loan amount to total assets ratio in the current year. We further consider the return on total assets $(R O A)$ of the enterprise, expressed as the ratio of enterprise net profit to total assets.

Referring to the method of $\mathrm{Xu}$ and Cui(2020), we further add the following prefectural city-level variables: the level of financial development (Credit), measured by the ratio of total loans from all financial institutions in the region to regional GDP; the level of infrastructure (Infrastructure), measured by the number of telephone 
subscribers; and the fiscal expenditure of the prefecture-level city (Fiscal), measured by the current year's fiscal expenditure. All variables are taken as natural logarithms, except for the level of financial development. The results in row (2) of Table 3 show that the regression coefficients of DID change very little in comparison to those in Table 2 after we control for municipality- and firm-level variables, indicating that these potential omitted variables do not impact the basic findings.

\subsubsection{Impact of the $\mathrm{LCPC}$ on total $\mathrm{SO}_{2}$ and $\mathrm{CO}_{2}$ emissions at the municipal level}

415 A potential limitation of using firm-level data is that we can only observe the impact on existing firms. However, environmental regulations may also lead to closures and entry restrictions among industrial firms if the cost of enhanced environmental regulations is so large that firms cannot continue to be profitable (Liu et al. 2021). row (3) of Table 3. The LCPC has a significant effect on $\mathrm{SO}_{2}$ and $\mathrm{CO}_{2}$ emissions, the coefficients of the doubledifference term of $\mathrm{SO}_{2}$ emissions in prefecture-level cities are all significantly positive at the $1 \%$ level, and the coefficients of the double-difference term of $\mathrm{CO}_{2}$ in prefecture-level cities are all significantly negative at the $1 \%$ level. This indicates that the LCPC decreases $\mathrm{CO}_{2}$ emissions but increases $\mathrm{SO}_{2}$ emissions. This result is consistent with the previous analysis. Therefore, the results of the firm-level analysis are reasonable.

\subsubsection{Alternative explanatory variable}

Other unobservable factors have the potential to confound the conclusions of the main regression model. In this 
robustness of the benchmark results, we replace the explanatory variables in model (1) here with the logarithm of

430 NOx emissions to examine the effect of the LCPC on the $\mathrm{SO}_{2}$ emissions of enterprises, and the regression results

431 are shown in row (4) of Table 3. The coefficients of the double-difference terms of nitrogen oxide emissions are all

432 significantly positive at the $1 \%$ level. This indicates that the LCPC increases the emissions of pollutant gases other

433 than $\mathrm{SO}_{2}$ gas in the enterprise. This corroborates the robustness of the above baseline analysis.

\subsection{Mechanisms}

The above analysis shows that the implementation of the LCPC significantly promotes $\mathrm{SO}_{2}$ emissions from heavy polluters. Therefore, what are the specific transmission mechanisms? In other words, what are the key variables that the $\mathrm{LCPC}$ affects to change the level of enterprise $\mathrm{SO}_{2}$ emissions?

\subsubsection{Impact of the LCPC on abatement inputs}

441 Given that we have rich and detailed information on enterprise-level production and pollution in relation to each

442 production process, including the amount of pollution generated in the enterprise's production process and emission

443 reduction facilities, we can measure the enterprise's financial investment in controlling $\mathrm{CO}_{2}$ and $\mathrm{SO}_{2}$ (Liu et al.

444 2021). The total corporate environmental protection input is influenced by corporate output (Lannelongue et al.

445 2015), on the basis of which we construct a proxy variable for total corporate environmental protection input. In this

446 paper, the provinces and cities included in the scope of the first two rounds of low-carbon pilot projects are used as

447 the treatment group, and the remaining provinces and cities are used as the control group. To analyze the mechanism

448 whereby the LCPC influences enterprise production, we take the increase in the amount of end-of-pipe equipment to

449 control $\mathrm{CO}_{2}$ and $\mathrm{SO}_{2}$ emissions is taken as the proxy variable for enterprise capital investment to control $\mathrm{CO}_{2}$ and 
$\mathrm{SO}_{2}$ emissions, and enterprise output is the proxy variable for total enterprise environmental protection input. The

specific model settings are as follows:

$\ln \left(M_{j}\right)_{i t}=\beta_{1}+\beta_{2} D_{I} D_{i t}+\beta_{3}$ treat $_{i t}+\beta_{4}$ post $_{i t}+\beta_{5} Z+\mu_{i}+\mu_{t}+\varepsilon_{i t}$

$$
\ln \left(M_{j}\right)_{i t} \text { is the logarithm of the amount of equipment for pollutant } j \text { of enterprise } i \text { in year } t \text {. If } j=1 \text {, }
$$

$\ln \left(M_{1}\right)_{i t}$ refers to the total environmental protection input of enterprise $i$ in year $t$. If $j=2, \ln \left(M_{2}\right)_{i t}$ refers to the logarithm of the amount of $\mathrm{CO}_{2}$ equipment used by enterprise $i$ in year $t$; if $j=3, \ln \left(M_{3}\right)_{i t}$ refers to the logarithm of the amount of $\mathrm{SO}_{2}$ equipment used by enterprise $i$ in year $t$. The other variables are as in model (1).

From Table 4 (1), we find that the coefficient of total environmental protection investment of heavily polluting enterprises in pilot areas after the implementation of the LCPC is 0.021 and significant at the $1 \%$ level, indicating that the low-carbon pilot reform increases the total environmental protection investment of heavily polluting enterprises in the jurisdiction by $2.1 \%$. From Table 4 (2), we find that the reform causes a significant increase of $4.5 \%$ in capital investment for $\mathrm{CO}_{2}$ treatment by heavily polluting enterprises in the jurisdiction; this figure is higher than the growth rate of total environmental protection investment. From Table 4 (3), we find that the reform does not significantly increase capital investment in $\mathrm{SO}_{2}$ treatment by heavy polluters in the jurisdiction. Under normal circumstances, the growth rates of $\mathrm{SO}_{2}$ - and $\mathrm{CO}_{2}$-related capital investment and total environmental protection investment are similar; however, implementation of the LCPC makes the growth rate of $\mathrm{CO}_{2}$-related investment much higher than that of total environmental protection investment, crowding out $\mathrm{SO}_{2}$-related investment, so that the latter does not increase significantly. This naturally leads $\mathrm{SO}_{2}$ emissions to increase. Thus, hypothesis 2 is verified.

Table 4. Total investment in environmental protection, capital investment in $\mathrm{CO}_{2}$ control and capital investment in $\mathrm{SO}_{2}$ control 


\begin{tabular}{lccc}
\hline & $(1)$ & $(2)$ & $(3)$ \\
& $\ln \left(\mathrm{M}_{1}\right)$ & $\ln \left(\mathrm{M}_{2}\right)$ & $\ln \left(\mathrm{M}_{3}\right)$ \\
\hline DID & $0.021^{* * *}$ & $0.045^{* * *}$ & 0.002 \\
& $(0.009)$ & $(0.005)$ & $(0.002)$ \\
Constant & $5.48^{* * *}$ & -0.156 & $-0.157^{* * *}$ \\
& $(0.187)$ & $(0.102)$ & $(0.044)$ \\
\hline City FE & YES & YES & YES \\
Firm FE & YES & YES & YES \\
Year FE & YES & YES & YES \\
Observations & 203673 & 214800 & 214800 \\
R squared & 0.162 & 0.371 & 0.064 \\
\hline
\end{tabular}

471

472 4.3.2. Impact of the low-carbon finance policy

473 The low-carbon pilot regions have all deployed low-carbon financial policies, aiming to provide financial support

474 for the low-carbon transition in the pilot regions. Such policies can facilitate financing for enterprises (Xu and Cui

475 2020) and alleviate their financial pressure in the process of managing $\mathrm{CO}_{2}$ emissions, which in turn encourages

476 enterprises to increase their financial investment in managing $\mathrm{CO}_{2}$ but reduce their investment in $\mathrm{SO}_{2}$

477 management. Here, overall credit at the municipal level is used as a proxy variable for low-carbon financial policy

478 to test whether implementation of the LCPC leads enterprises to increase their investment in $\mathrm{CO}_{2}$ treatment through

479 financial policy and produce a crowding-out effect on investment in $\mathrm{SO}_{2}$ treatment. In this paper, on the basis of

480 model (9), we take the increase in the amount of end-of-pipe equipment for $\mathrm{CO}_{2}$ and $\mathrm{SO}_{2}$ treatment as the proxy

481 variable for the increase in enterprise financial investment in $\mathrm{CO}_{2}$ and $\mathrm{SO}_{2}$ treatment and add the loan variable

482 Inloanct at the municipal level to construct a triple-difference model as follows:

$483 \ln \left(M_{j}\right)_{i t}=\alpha+\beta_{1}$ DID $_{i t} * \operatorname{lnloan}_{c t}+\beta_{2}$ Post $_{i t} * \operatorname{lnloan}_{c t}+\beta_{23}$ Treat $_{i t} * \operatorname{lnloan}_{c t}$

$484+\gamma Z+\mu_{i}+\mu_{t}+\varepsilon_{i t}$

485 where $\operatorname{lnloan}_{c t}$ is the logarithm of the balance of all loans of financial institutions in city $c$ at the end of year $t$. 
486

Table 5. Low-carbon financial policy impacts

\begin{tabular}{lcc}
\hline & $(1)$ & $(2)$ \\
& $\ln \left(\mathrm{M}_{1}\right)$ & $\ln \left(\mathrm{M}_{2}\right)$ \\
\hline Incityloan_DID & $0.023^{* * *}$ & $-0.006^{* * *}$ \\
Constant & $(0.003)$ & $(0.001)$ \\
& $-0.216^{*}$ & $-0.244^{* * *}$ \\
City FE & $(0.116)$ & $(0.050)$ \\
Firm FE & YES & YES \\
Year FE & YES & YES \\
Observations & YES & YES \\
R squared & 214800 & 214800 \\
\hline
\end{tabular}

\section{Effect heterogeneity}

499 Although the previous analyses have demonstrated that the LCPC promotes corporate $\mathrm{SO}_{2}$ emissions, do different 500 types of companies respond differently to this policy? Do different regions implement the policy in different ways? 
501 Do different degrees of fiscal decentralization have an impact on the effectiveness of policy implementation? This

502 section discusses heterogeneity in the policy effect in terms of the intrinsic characteristics of firms, regions, and the

503 degree of fiscal decentralization.

\subsection{Heterogeneity by ownership type}

506 Compared with that in developed countries in Europe and the United States, legal and institutional development in

507 developing countries is weaker, and regionally based environmental policies often face greater obstacles and

508 difficulties at the implementation level (Greenstone and Hanna 2014; Li et al. 2016). In the case of enterprises with

509 different ownership types, state-owned enterprises (SOEs) are those invested in or controlled by the central or local

510 governments; SOEs have a significant advantage in resource allocation, especially in terms of receiving financial

511 support (Allen et al. 2005), and are not particularly sensitive to either the compliance cost pressure from

512 environmental regulations or the economic innovation incentives provided by government finance to support

513 environmental protection. In contrast, non-SOEs are self-sustaining, and they face greater expectations to improve

514 their environmental performance through environmental technology innovation (Ren et al. 2019). On the other hand,

515 in terms of information on resource reallocation and technological improvements, nonstate enterprises are more

516 flexible in adjusting and reforming their internal institutional mechanisms and the flow of production factors within

517 the enterprise in response to compliance pressures and are more efficient in reallocating resources under

518 environmental regulations than state-owned enterprises. Therefore, here, the overall sample is divided into three

519 subsamples (state-owned enterprises, private enterprises and foreign enterprises) and the benchmark model re-

520 estimated to further investigate whether the LCPC produces heterogeneous $\mathrm{SO}_{2}$ emission effects for different types

521 of enterprises. 
523 in the subsample of state-owned enterprises corresponding to column (1); the double-difference term coefficient is

524 significantly positive for the private enterprises in column (2), but the rate of increase is much lower than that in

525 state-owned enterprises. In addition, the coefficient of the double-difference term is not significant for the subsample

526 of foreign firms in column (3). This suggests that there is indeed heterogeneity at the level of enterprise ownership

527 type in the effect of the LCPC on enterprises' exhaust emissions: the $\mathrm{LCPC}$ more significantly exacerbates the $\mathrm{SO}_{2}$

528 emissions of state-owned enterprises and private enterprises, and the increase is larger in the former than in the

529 latter. The possible reason is that SOEs have stronger path-dependent effects and are generally subject to weaker

530 environmental regulation constraints due to their important responsibilities in local economic development. This is

531 consistent with the findings of Ren et al. (2019), Han and Sang (2018), etc. Ren et al. (2019) find that the emissions

532 trading system has a greater effect on the total factor productivity of non-SOEs than SOEs. Han and Sang (2018)

533 find that SOEs are less motivated to move their products in cleaner directions when facing environmental regulatory

534 constraints because their own political power can reduce the pressure from regulation. For foreign firms, the effect

535 of the LCPC on $\mathrm{SO}_{2}$ emissions is not significant: it is known that foreign firms have better environmental

536 performance than domestic firms. Because foreign firms are relatively more technologically advanced, have stronger

537 operational capabilities, and are more aware of environmental protection needs, environmental regulations have little

538 effect on their environmental investment and thus no significant effect on their $\mathrm{SO}_{2}$ emissions. Therefore, non-

539 SOEs' $\mathrm{SO}_{2}$ emissions are more likely to be exacerbated by the LCPC than SOEs' in high-pollution industries.

540 Table 6. Heterogeneity by ownership

(1)

State-owned

enterprises
(2)

Private

enterprises
(3)

Foreign-owned

enterprises 


\begin{tabular}{lccc}
\hline DID & $0.275^{* * *}$ & $0.167^{* * *}$ & -0.007 \\
Constant & $(0.066)$ & $(0.015)$ & $(0.035)$ \\
& $9.981^{* * *}$ & $8.779^{* * *}$ & $8.443^{* * *}$ \\
City FE & $(1.032)$ & $(0.309)$ & $(0.767)$ \\
Firm FE & YES & YES & YES \\
Year FE & YES & YES & YES \\
Observations & YES & YES & YES \\
R squared & 14601 & 127711 & 22127 \\
\hline
\end{tabular}

\section{$542 \quad$ 5.2. Heterogeneity by region}

543 Considering that the economic development conditions and industrial bases of each region differ greatly, the LCPC

544 may have heterogeneous effects on enterprise emissions across regions, and thus, we divide the sample into eastern,

545 central and western regions. The results in columns (1)-(3) of Table 7 show that the coefficients of DID are

546 significant at $0.105,0.178$ and 0.274 , respectively; i.e., the pilot LCPC reform has a significant effect on enterprise

547 emissions in the east, central region and west of the country. The effect gradually increases from east to west, due to

548 the relatively greater development and stronger business operation capacity in the east, stronger governance capacity

549 of the eastern government, and better policies under the low-carbon pilot reform. The effect of the LCPC in the

550 central and western parts is relatively worse.

551 Table 7. Heterogeneity by region

\begin{tabular}{lccc}
\hline & $(1)$ & $(2)$ & $(3)$ \\
& EAST & MID & WEST \\
\hline DID & $0.105^{* * *}$ & $0.178^{* * *}$ & $0.274^{* * *}$ \\
Constant & $(0.015)$ & $(0.039)$ & $(0.048)$ \\
& $7.822^{* * *}$ & $11.188^{* * *}$ & $11.024^{* * *}$ \\
\hline City FE & $(0.351)$ & $(0.654)$ & $(1.011)$ \\
Firm FE & YES & YES & YES \\
Year FE & YES & YES & YES \\
Observations & YES & YES & YES \\
& 105129 & 37672 & 21687
\end{tabular}




\begin{tabular}{llll} 
R squared & 0.861 & 0.818 & 0.764 \\
\hline
\end{tabular}

\section{Further discussion}

\subsection{Impact of fiscal decentralization}

556 Fiscal decentralization also has implications for environmental regulation. Fiscal decentralization gives local

557 governments fiscal autonomy and a "residual claim" on revenues so that they can implement public policies that suit

558 their interests relatively independently to achieve their policy targets for $\mathrm{CO}_{2}$ reduction. Fiscal decentralization

559 gives local governments the right to dispose of resources to ensure the effectiveness of incentives in political

560 promotion tournaments (Zhang 2016). Because the LCPC also involves assessment of local governments, LCPC

561 regional governments have incentives to use the fiscal autonomy granted by fiscal decentralization to meet carbon

562 targets, resulting in fiscal support that inhibits control of $\mathrm{SO}_{2}$. Fiscal policy focused on reducing $\mathrm{CO}_{2}$ may crowd

563 out enterprises' $\mathrm{SO}_{2}$-related investment, which in turn inhibits enterprises' management of $\mathrm{SO}_{2}$. In short, in low-

564 carbon pilot regions, because of the pressure of performance assessment, local governments are more willing to

565 adopt fiscal tools to reduce $\mathrm{CO}_{2}$ emissions, which suppresses fiscal support for $\mathrm{SO}_{2}$ treatment. The higher the

566 degree of fiscal decentralization, the greater is the fiscal autonomy of the region and the fiscal support for reducing

$567 \mathrm{CO}_{2}$ emissions, which in turn discourages enterprises from investing in $\mathrm{SO}_{2}$ control.

569 indicators: expenditure indicators, revenue indicators and fiscal autonomy indicators. This paper draws on the

570 approach of Guo et al. (2020) to construct fiscal decentralization $(F D)$ indicators for prefecture-level municipalities.

571 The higher is the degree of fiscal decentralization, the greater the fiscal autonomy of the region, the greater the fiscal 
support for reducing $\mathrm{CO}_{2}$ emissions, and the greater the crowding-out effect on the enterprises' investment in

managing $\mathrm{SO}_{2}$ emissions. In this paper, based on model (9), we take the increase in the amount of end-of-pipe

equipment to control $\mathrm{CO}_{2}$ and $\mathrm{SO}_{2}$ as proxy variables for enterprises' inputs to control $\mathrm{CO}_{2}$ and $\mathrm{SO}_{2}$ and add the

fiscal decentralization variable $F D$ at the municipal level to construct a triple-difference model as follows:

$\ln \left(M_{j}\right)_{i t}=\alpha+\beta_{1} D I D_{i t} * \mathrm{~F} D_{c t}+\beta_{2}$ Post $_{i t} * \mathrm{~F} D_{c t}+\beta_{3}$ Treat $_{i t} * \mathrm{~F} D_{c t}+\beta_{4} D I D$

$+\gamma Z+\mu_{i}+\mu_{t}+\varepsilon_{i t}$

where $\mathrm{F} D_{c t}$ is the fiscal weight of municipality $c$ in year $t . \ln \left(M_{j}\right)_{i t}$ is the logarithm of the amount of equipment

in enterprise $i$ in year $t$. If $j=1, \ln \left(M_{1}\right)_{i t}$ refers to the logarithm of the amount of $\mathrm{CO}_{2}$ equipment in enterprise $i$ in

regression results are shown in Table 8. The coefficient of the triple-difference term is significantly positive in

column (1), which indicates that by enhancing financial and taxation support at the municipal level, the LCPC leads

enterprises to increase their investment in $\mathrm{CO}_{2}$ control; on the other hand, it can be seen from Table 8 (2) that the

The possible reason is that the fiscal support policies proposed by the pilot regions in their respective low-carbon

Table 8. Impact of fiscal decentralization

\begin{tabular}{lcc}
\hline & $(1)$ & $(2)$ \\
& $\ln \left(\mathrm{M}_{1}\right)$ & $\ln \left(\mathrm{M}_{2}\right)$ \\
\hline FD_DID & $0.336^{* * *}$ & 0.003 \\
& $(0.026)$ & $(0.011)$ \\
Constant & $-0.543^{* * *}$ & $-0.497^{* * *}$ \\
& $(0.159)$ & $(0.067)$ \\
\hline City FE & YES & YES
\end{tabular}




\begin{tabular}{lcc} 
Firm FE & YES & YES \\
Year FE & YES & YES \\
Observations & 152170 & 152170 \\
R squared & 0.441 & 0.085 \\
\hline
\end{tabular}

\subsection{Impact of market segmentation}

591 Fiscal decentralization can cause local governments to compete with each other, which in turn causes market

592 segmentation (Deng and Yang 2019). Is there a moderating effect of this market segmentation behavior on the

593 LCPC's influence on enterprise inputs into $\mathrm{CO}_{2}$ and $\mathrm{SO}_{2}$ management? In this paper, an interaction term between a

594 local market segmentation indicator and the LCPC indicator is introduced into model (9) to test this conjecture, and

595 a triple-difference model is constructed as follows:

$\ln \left(M_{j}\right)_{i t}=\alpha+\beta_{1} D I D_{i t} * S E G_{c t}+\beta_{2}$ Post $_{i t} * S E G_{c t}+\beta_{3}$ Treat $_{i t} * S E G_{c t}+\beta_{4} D I D$

$597+\gamma Z+\mu_{i}+\mu_{t}+\varepsilon_{i t}$

(11). The regression results are shown in Table 9. The coefficient of the triple-difference term is not significant in

$601 \mathrm{SO}_{2}$ control through the mediating effect of market segmentation, exacerbating enterprises' $\mathrm{SO}_{2} \quad$ emissions. The

602 possible reason is that $\mathrm{LCPC}$ has different assessments of local governments' efforts to control $\mathrm{CO}_{2}$ and $\mathrm{SO}_{2}$

603 intensity, and local governments have more incentives to suppress $\mathrm{SO}_{2}$ control inputs through market segmentation.

604 Table 9. Impact of market segmentation

(1)

\begin{tabular}{lcc} 
& $\ln \left(\mathrm{M}_{1}\right)$ & $\ln \left(\mathrm{M}_{2}\right)$ \\
\hline SEG_DID & -0.014 & $-0.040^{* * *}$ \\
& $(0.034)$ & $(0.014)$ \\
Constant & 0.191 & $-0.549^{* * *}$
\end{tabular}


$(0.148)$

$(0.063)$

\begin{tabular}{lcc} 
City FE & YES & YES \\
Firm FE & YES & YES \\
Year FE & YES & YES \\
Observations & 152170 & 152170 \\
R squared & 0.441 & 0.085 \\
\hline
\end{tabular}

605

\section{Conclusion}

607 This paper focuses on the impact of the $\mathrm{LCPC}$ on the $\mathrm{SO}_{2}$ emissions of heavily polluting enterprises. The findings

608 include the following: First, the LCPC has significantly exacerbated $\mathrm{SO}_{2}$ emissions among heavily polluting enterprises in the pilot areas, and the environmental treatment effect of the LCPC needs to be improved. Second, the main transmission mechanism is the loan support provided through low-carbon financial policies under the reform

611 for the treatment of $\mathrm{CO}_{2}$ inputs of heavily polluting enterprises in pilot areas, which inhibits support for $\mathrm{SO}_{2}$

612 treatment inputs. The $\mathrm{LCPC}$ has a crowding-out effect, with $\mathrm{CO}_{2}$ inputs displacing $\mathrm{SO}_{2}$ inputs in high-pollution

613 industries in the pilot areas, which in turn has increased enterprises $\mathrm{SO}_{2}$ emissions. Third, the LCPC has

614 significantly aggravated the $\mathrm{SO}_{2}$ emissions of enterprises across the eastern, central and western regions, on the one

615 hand, and private and state-owned enterprises, on the other, with an increasing trend across these two sets of

616 subsamples. Fourth, it is further found that fiscal decentralization and the market segmentation resulting from fiscal

617 decentralization mediate the effect on enterprise $\mathrm{CO}_{2}$ control and inhibit inputs into $\mathrm{SO}_{2}$ control. 
622 promoting economic and social change has become increasingly significant, and many cities around the world have

623 constructed low-carbon zones as an important means of enhancing the competitiveness of cities and even countries.

624 Compared with those of developed countries, the legal and institutional development of developing countries is

625 weaker, and area-based environmental policies often face greater obstacles and difficulties at the implementation

626 level. The results of this paper suggest that the effectiveness of low-carbon policies, a type of area-based

627 environmental policy, needs to be improved in the largest developing countries, and the findings of this study are

628 useful for us to re-examine the effectiveness of enterprise environmental governance under the LCPC. $\mathrm{CO}_{2}$ treatment inputs in the pilot areas for heavy polluters inhibits loan support for $\mathrm{SO}_{2}$ treatment inputs. The growth rate of investment in $\mathrm{CO}_{2}$ mitigation among heavy polluters in the pilot areas is much higher than that in total environmental protection inputs, but the investment growth rate of $\mathrm{SO}_{2}$ inputs does not increase significantly. This suggests that the design and planning of low-carbon policies should include clearer and more comprehensive planning and support for innovation and technological upgrading to achieve synergistic management of the ecological environment and climate change so that these enterprises can achieve the goal of reducing both greenhouse gas and pollution emissions. Third, the results obtained based on the heterogeneity analysis show that the LCPC's effects vary greatly by geography, ownership type and level of fiscal autonomy. To strengthen the ecological environment, we should use flexible and appropriate environmental regulations to give firms continuous innovation incentives. This paper finds that the effect of the LCPC varies among firms by ownership, geographical area and fiscal autonomy level: this

641 difference also reflects that the government needs to make environmental policies with greater consideration of 642 different firms characteristics. The design of the LCPC system should take into account these aspects, and in 
643 addition to creating a level playing field for less developed regions and nonstate enterprises, the monitoring

644 mechanism can be designed to apply greater compliance pressure on less developed regions, regions with greater

645 fiscal autonomy, and state-owned enterprises.

646 Fourth, based on further research results, fiscal decentralization and the associated mediating effect of

647 market segmentation promote inputs into enterprise $\mathrm{CO}_{2}$ governance and inhibit inputs into enterprise $\mathrm{SO}_{2}$

648 governance. We should increase marketization in the economy, reduce unnecessary government intervention, and in

649 general leverage the role of the market in resource allocation.

651 polluting enterprises and that the ecological and environmental management effect of the LCPC needs to be

652 improved. China's sustained high economic growth for more than 40 years has brought about severe resource and

653 environmental pressure; alleviating this pressure requires continuous efforts and reforms, and the LCPC is one of the

654 flagship efforts among many environmental reforms. A scientific and systematic assessment of the effectiveness of

655 the regional-based LCPC provides experience and inspiration to formulate relevant environmental pollution

656 prevention and control policies in developing countries in the short term; in the long term, it is of great practical

657 significance to help developing countries to build ecological civilization as a millennium plan for sustainable

658 development.

661 Allen F, Qian J, Qian M (2005) Law, finance, and economic growth in China. J Financ Econ 77:57-116. https://doi.org/10.1016/j.jfineco.2004.06.010 
Public Econ 79:265-295. https://doi.org/10.1016/s0047-2727(99)00101-2

Brandt L, Van Biesebroeck J, Wang L, Zhang Y (2017) WTO accession and performance of Chinese manufacturing firms. Am Econ Rev 107:2784-2820. https://doi.org/10.1257/aer.20121266

Brandt L, Van Biesebroeck J, Zhang Y (2012) Creative accounting or creative destruction? Firm-level productivity growth in Chinese manufacturing. J Dev Econ 97:339-351. https://doi.org/10.1016/j.jdeveco.2011.02.002

Brown, R. S., \& Christensen, L. R. (1980). Estimating elasticities of substitution in a model of partial static equilibrium: An application to US agriculture, 1947-1974 (No. 2242-2019-3082).

Bu M, Qiao Z, Liu B (2020) Voluntary environmental regulation and firm innovation in China. Econ Model 89:1018. https://doi.org/10.1016/j.econmod.2019.12.020

Cai WX, Ni XR, Zhao P, Yang TT (2019) The impact of business groups on innovation outputs: evidence from Chinese manufacturing firms. China Ind Prod :137-155. DOI:10.19581/j.cnki.ciejournal.2019.01.008

Chen H, Guo W, Feng X, Wei W, Liu H, Feng Y, Gong W (2021) The impact of low-carbon city pilot policy on the total factor productivity of listed enterprises in China. Resour Conserv Recycl 169:105457. https://doi.org/10.1016/j.resconrec.2021.105457

Chen YJ, Li P, Lu Y (2018a) Career concerns and multitasking local bureaucrats: evidence of a target-based performance evaluation system in China. J Dev Econ 133:84-101. https://doi.org/10.1016/j.jdeveco.2018.02.001

Chen Z, Kahn ME, Liu Y, Wang Z (2018b) The consequences of spatially differentiated water pollution regulation in China. J Environ Econ Manag 88:468-485. https://doi.org/10.1016/j.jeem.2018.01.010

Cole MA, Elliott RJ (2007) Do environmental regulations cost jobs? An industry-level analysis of the UK. BE J Econ Anal Policy 7. https://doi.org/10.2202/1935-1682.1668 
685

686

687

688

689

690

691

692

693

694

695

696

697

698

699

700

701

702

703

704

705
Copeland BR, Taylor MS (2013) Trade and the environment. Princeton University Press, New Jersey, NJ

Dai R, Cao JH (2015) The effect of China's first low-carbon pilot: DID estimation of five cities and eight provinces.

Sci Technol Manag Res 12:56-61.

https://kns.cnki.net/kcms/detail/detail.aspx?FileName=KJGL201512011\&DbName=CJFQ2015

Deng, H. H., \& Yang, L. X. (2019). Haze governance, local competition and industrial green transformation. China

Ind. Econ., 10, 118-136.

Ellison RB, Greaves SP, Hensher DA (2013) Five years of London's low emission zone: effects on vehicle fleet composition and air quality. Transp Res D Transp Environ 23:25-33.

https://doi.org/10.1016/j.trd.2013.03.010

Feng T, Lin Z, Du H, Qiu Y, Zuo J (2021) Does low-carbon pilot city program reduce carbon intensity? Evidence from Chinese cities. Res Int Bus Finance 58:101450. https://doi.org/10.1016/j.ribaf.2021.101450

Gehrsitz M (2017) The effect of low emission zones on air pollution and infant health. J Environ Econ Manag

83:121-144. https://doi.org/10.1016/j.jeem.2017.02.003

Greenstone M, Hanna R (2014) Environmental regulations, air and water pollution, and infant mortality in India.

Am Econ Rev 104:3038-3072. https://doi.org/10.1257/aer.104.10.3038

Guo S, Wen L, Wu Y, Yue X, Fan G (2020) Fiscal decentralization and local environmental pollution in China. Int J

Environ Res Public Health 17:8661. https://doi.org/10.3390/ijerph17228661

Han C, Sang RC (2018) Enterprises’ product switching and product quality improvement under environmental regulation. China Ind Econ 2:43-62. DOI:10.19581/j.cnki.ciejournal.20180206.002

Hao Y, Peng H, Temulun T, Liu LQ, Mao J, Lu ZN, Chen H (2018) How harmful is air pollution to economic development? New evidence from PM2.5 concentrations of Chinese cities. J Clean Prod 172:743-757. 
https://doi.org/10.1016/j.jclepro.2017.10.195

707 Hong M, Chen S, Zhang K (2021) Impact of the "low-carbon city pilot" policy on energy intensity based on the empirical evidence of Chinese cities. Front Environ Sci 9:257. https://doi.org/10.3389/fenvs.2021.717737

Huang J, Cao J, Hasan T, Zhao J (2021) Low-carbon city initiatives and firm risk: a quasi-natural experiment in China. J Financ Stab 57:100949. https://doi.org/10.1016/j.jfs.2021.100949

711 Ji X, Umar M, Ali S, Ali W, Tang K, Khan Z (2021) Does fiscal decentralization and eco-innovation promote https://doi.org/10.1002/sd.2132

Jin G, Shen KR (2018) Polluting thy neighbor or benefiting thy neighbor: enforcement interaction of environmental DOI:10.19744/j.cnki.11-1235/f.2018.0032

Khanna N, Fridley D, Hong L (2014) China's pilot low-carbon city initiative: a comparative assessment of national

Levinson A (2009) Technology, international trade, and pollution from US manufacturing. Am Econ Rev 99:21772192. https://doi.org/10.1257/aer.99.5.2177 
728

Li W, Zheng M (2016) Is it substantive innovation or strategic innovation? Impact of macroeconomic policies on micro-enterprises' innovation. Econ Res J 4:60-73. https://kns.cnki.net/kcms/detail/detail.aspx?FileName=JJYJ201604005\&DbName=CJFQ2016

Lin J, Jacoby J, Cui S, Liu Y, Lin T (2014) A model for developing a target integrated low carbon city indicator system: the case of Xiamen, China. Ecol Indic 40:51-57. https://doi.org/10.1016/j.ecolind.2014.01.001

Liu M, Tan R, Zhang B (2021a) The costs of “blue sky”: environmental regulation, technology upgrading, and labor demand in China. J Dev Econ 150:102610. https://doi.org/10.1016/j.jdeveco.2020.102610

Liu W, Qin B (2016) Low-carbon city initiatives in China: a review from the policy paradigm perspective. Cities 51:131-138. https://doi.org/10.1016/j.cities.2015.11.010

Meuleman M, De Maeseneire W (2012) Do R\&D subsidies affect SMEs' access to external financing? Res Policy 41:580-591. https://doi.org/10.1016/j.respol.2012.01.001

Mujtaba G, Shahzad SJH (2021) Air pollutants, economic growth and public health: implications for sustainable development in OECD countries. Environ Sci Pollut Res 28:12686-12698. https://doi.org/10.1007/s11356-020-11212-1

NDRC (2014) China's policies and actions on climate change. NDRC, Beijing

Peng J, Li J, Ding Y (2020) Influence and mechanism analysis of pilot policies of low-carbon cities on. J Urban Issues 10:88-97. DOI:10.13239/j.bjsshkxy.cswt.201010

Qi Y (2013) Annual review of low-carbon development in China: 2010. World Scientific, Singapore

Ren SG, Zheng JJ, Liu DH, Chen X (2019) Does emissions trading system improve firm's total factor productivityevidence from Chinese listed companies. China Ind Econ:5-23. 
DOI:10.19581/j.cnki.ciejournal.2019.05.001

749

750

751

752

753

754

755

756

757

758

759

760

761

762

763

764

765

766

767

768

Sinn HW (2008) Public policies against global warming: a supply side approach. Int Tax Public Finance 15:360-

394. https://doi.org/10.1007/s10797-008-9082-z

Song H, Sun Y, Chen D (2019) Assessment for the effect of government air pollution control policy: empirical evidence from "low-carbon city" construction in China. Manag World 35:95-108.

DOI: 10.19744/j.cnki.11-1235/f.2019.0082

Song Q, Liu T, Qi Y (2021) Policy innovation in low carbon pilot cities: lessons learned from China. Urban Clim 39:100936. https://doi.org/10.1016/j.uclim.2021.100936

Song Q, Zhou N, Liu T, Siehr SA, Qi Y (2018) Investigation of a "coupling model” of coordination between lowcarbon development and urbanization in China. Energy Policy 121:346-354.

https://doi.org/10.1016/j.enpol.2018.05.037

Tan S, Yang J, Yan J, Lee C, Hashim H, Chen B (2017) A holistic low carbon city indicator framework for sustainable development. Appl Energy 185:1919-1930. https://doi.org/10.1016/j.apenergy.2016.03.041

Wang M, Li Y, Li M, Shi W, Quan S (2019) Will carbon tax affect the strategy and performance of low-carbon technology sharing between enterprises? J Clean Prod 210:724-737. https://doi.org/10.1016/j.jclepro.2018.10.321

Wang Y, Song Q, He J, Qi Y (2015) Developing low-carbon cities through pilots. Clim Policy 15:S81-S103. https://doi.org/10.1080/14693062.2015.1050347

World Health Organization (2016) Ambient air pollution: a global assessment of exposure and burden of disease. World Health Organization: 1-2. https://www.who.int/news/item/12-05-2016-air-pollution-levels-rising-inmany-of-the-world-s-poorest-cities 
769 Wolff H (2014) Keep your clunker in the suburb: low-emission zones and adoption of green vehicles. Econ J

771 Xu J, Cui JB (2020) Low-carbon cities and firms' green technological innovation. China Ind Econ :178-196

772 Yu YZ, Zhang SH (2017) Urban housing prices, purchase restriction policy and technological innovation. China Ind Econ 6:100-118. DOI:10.19581/j.cnki.ciejournal.2017.06.020

Zhang B, Chen X, Guo H (2018) Does central supervision enhance local environmental enforcement? Quasiexperimental evidence from China. J Public Econ 164:70-90. https://doi.org/10.1016/j.jpubeco.2018.05.009

Zhang H (2016) Strategic interaction of regional environmental regulation: an explanation on the universality of incomplete enforcement of environmental regulation. China Ind Econ 7:74-90. DOI:10.19581/j.cnki.ciejournal.2016.07.006 structure: a quasi-natural experiment evidence from China. Environ Sci Pollut Res 27:20392-20409. https://doi.org/10.1007/s11356-020-08462-4 


\section{Availability of data and materials}

The dataset used during the current study are available from the corresponding author on reasonable request.

\section{Funding}

This paper was supported by the National Natural Science Foundation of China (grant number: 42071161), the

National Social Science Foundation of China (grant number: 20BTJ011), the General Project of Hunan Provincial

Philosophy and Social Science Planning (grant number: XSP20YBC051), and the General Project of Hunan

Provincial Education Department for Scientific Research (grant number: 19C1032).

\section{Author information}

\section{Affiliations}

School of Economics and Trade, Hunan University, Changsha 410205, Hunan, China

Ping Guo, Jin Li, Renrui Xiao \& Donghao Duan

School of Economics and Trade, Hunan University of Technology and Business, Changsha 410205, Hunan, China

Jinsong Kuang \& Yifei Zhu

School of Public Administration, Hunan University, Changsha 410205, Hunan, China

Baocong Huang

\section{Contributions}

Ping Guo: conceptualization, supervision; Jin Li: methodology, software;,formal analysis;,data curation,writing—

original draft, writing—review and edit,visualization;Jinsong Kuang: methodology; writing—review and edit;

validation; funding acquisition;Renrui Xiao: validation, writing—review and edit; Donghao Duan: methodology,

validation; Baocong Huang: methodology, validation; Yifei Zhu: methodology, validation. 
Ethics declarations

805 Ethical approval

$806 \quad$ Not applicable

807 Consent to participate

$808 \quad$ Not applicable

809 Consent to publish

$810 \quad$ Not applicable

$811 \quad$ Competing interests

812 The authors have no relevant financial or non-financial interests to disclose.

813 Ethics approval

$814 \quad$ Not applicable

815

816 